\title{
Simulador computacional para o Ensino de Física: o Sandbox como ambiente de criação
}

\author{
Allan H. Paza ${ }^{1}$, Elizabeth Matos Rocha ${ }^{1}$, Ariane Baffa Lourenço ${ }^{1}$, \\ Adailton José Alves da Cruz ${ }^{1}$, Fernando Cesar Ferreira ${ }^{1}$, Eriton Botero ${ }^{1}$ \\ ${ }^{1}$ Universidade Federal da Grande Dourados (UFGD) Dourados - MS - Brazil \\ \{adailtoncruz, fernandoferreira, arianelourenco\}@ufgd.edu.br \\ \{allanpaza, eritonbotero,elizabeth.matosrocha\}egmail.com
}

\begin{abstract}
This work discusses the use of a $3 D$ virtual environment in the formation of Physics teachers. Using a 3D simulation in the Sandbox platform, Bachelor's students in Physics of a federal public university were invited to work collaboratively, forming a group of two students, to solve a problem involving the projectile motion. Initial analysis shows that the chat tool allowed students a greater interaction collaborating in the learning process. In fact $79 \%$ of students felt that the experiment helped to understand the projectile motion concept.
\end{abstract}

Resumo. Este artigo discute o uso de um ambiente virtual 3D na formação de professores de Física. A partir de uma simulação 3D na plataforma Sandbox, duplas de alunos da Licenciatura em Física de uma universidade pública federal foram convidadas a trabalharem colaborativamente na resolução de um problema envolvendo o lançamento oblíquo de objetos. Análise inicial mostra que para os alunos a ferramenta de chat possibilitou uma maior interação com o colega colaborando no processo de aprendizagem. Ao todo $79 \%$ dos alunos consideraram que o experimento contribuiu para entender o conceito de lançamento de projétil.

\section{Introdução}

Se de um lado a velocidade e os avanços em Tecnologia da Informação tem impulsionado um aumento no uso do Ambiente Virtual de Aprendizagem-AVA, por outro se observa uma demanda crescente por ferramentas que potencializem as relações dos usuários com esses ambientes. Diferentes formas de comunicação, percepção, capacidade de agir, interferir no ambiente, e o realismo, podem contribuir para motivar e envolver o usuário no processo de construção do seu conhecimento. Uma área de investigação que tem se ocupando deste tema é a Interação Homem-Computador, a qual busca oferecer interfaces que contemplem diferentes formas ao usuário para interagir com a máquina. Neste processo, as interfaces que suportam interações multimodais avançam o conhecido padrão gráfico baseado em Janelas, Ícones, Menus e Ponteiros (padrão WIMP) implementando modos de comunicação mais intuitivos. Somando as interações multimodais aos ambientes virtuais imersivos obtém-se um mundo virtual (MV) que oferece ao usuário uma percepção de realismo não presenciada, em geral, nos AVA's.

Os usuários, habitantes destes MV's, são representados por modelos gráficos, denominados avatares que lhes possibilitam interagirem entre si e com o "mundo", podendo 
estas ações resultarem ou não em mudanças no MV. Quando se confere este tipo de autoridade ao usuário criam-se condições para que o mesmo sinta-se inserido no ambiente saindo da figura de espectador para ser um "criador" do mundo. Tais ambientes podem ser utilizados no processo de ensino de diferentes áreas do conhecimento, como a Física, pois podem trazer como benefícios: portabilidade, facilidade de comunicação via internet e redes sem fio, interatividade, modelagem matemática, compreensão dos fenômenos físicos etc ([Medeiros and de Medeiros 2002], [Yamamoto and Barbeta 2001], [Fonseca et al. 2013], [Frustaci et al. 2007], [Hohenfeld and Penido 2009]).

Fazendo um recorte para a formação de professores e o papel do laboratório de ensino de física [Arruda and Laburú 1998], um obstáculo para o aumento da oferta de cursos à distância de Física é a falta de estrutura e equipamentos de laboratórios de ensino nos polos de apoio presencial. Considerando este problema, acreditamos que fazer uso de simulações computacionais pode contribuir tanto para amenizar o quadro de falta de estrutura dos polos quanto para preparar o futuro professor para o uso da tecnologia em suas aulas. Assim, neste trabalho apresentamos os resultados do uso de um simulador de Física com alunos de uma universidade pública federal.

\section{Métodos}

O desenvolvimento do laboratório 3D de Física começou com a aprovação, em 2012, de projeto de pesquisa junto à Fundação de Apoio ao Desenvolvimento do Ensino, Ciência e Tecnologia do Estado de Mato Grosso do Sul (FUNDECT). O OpenSimulator foi o ambiente inicialmente escolhido para a construção dos ambientes. No entanto, ao longo de 2013 e parte de 2014 dificuldades para a programação e implementação de objetos e avatares dentro do ambiente foram detectadas. Isto levou a busca por novo ambiente de programação que pudesse atender aos requisitos do projeto. O Sandbox foi escolhido por fazer uso de novas tecnologias de desenvolvimento e, diferente do OpenSimulator, não ser necessário para o usuário final ter que baixar e instalar componentes para rodar as simulações. Assim, foi escolhida a temática "lançamento oblíquo de um objeto" para a simulação. Uma vez construído o simulador dentro do Sandbox, o mesmo foi utilizado com 14 alunos matriculados na disciplina de Produção de Material Didático, ofertada no curso de Licenciatura em Física de uma universidade pública do estado de Mato Grosso do Sul.

Na vivência, inicialmente, foi explicado aos alunos o objetivo da pesquisa e estes assinaram um termo de consentimento. Na sequência, os alunos, individualmente, responderam a um conjunto de questões online que envolviam sua aptidão com a Física e um pré-teste envolvendo conceitos relacionados a temática, e ao final da atividade o préteste foi reaplicado e também questões sobre o envolvimento dos alunos com o simulador. Neste trabalho apresentaremos o simulador construído e as respostas dos alunos quanto suas impressões em trabalharem com o simulador.

\section{Resultados e Discussão}

O Sandbox possui uma paleta de objetos que juntam modelos visuais e comportamentos os quais o usuário apenas precisa arrastar e soltar para que estes objetos complexos façam parte da cena. Ele também aproveita outros serviços da nuvem externa para facilitar o rastreamento de dados, importação e conversão de ativos, e gerenciamento de identidades. 
V Congresso Brasileiro de Informática na Educação (CBIE 2016)

Anais dos Workshops do V Congresso Brasileiro de Informática na Educação (CBIE 2016)

Com base nestas características elaboramos o simulador de lançamento oblíquo dentro do Sandbox. Para acessá-lo o usuário efetua um cadastro e ao se logar escolhe um avatar, e tem acesso a um quadro com as orientações sobre movimento, interação com os objetos e a questão de física que deve responder (Figura 1A). O aluno pode, então, inserir valores do ângulo de lançamento e velocidade inicial. É possível alterar a aceleração da gravidade para simular a situação em outros ambientes. Após esta etapa o usuário clica em "Lançar" e o objeto é lançado. A trajetória é traçada e um cronômetro registra o tempo de voo. Duas réguas, uma horizontal e outra vertical, podem ser utilizadas para medir o alcance e a altura máxima (Figura 1B). Nesta versão a simulação não leva em conta os efeitos da resistência do ar ou a forma do objeto. O simulador conta com uma ferramenta de chat em que os usuários podem trocar informações enquanto executam o experimento.
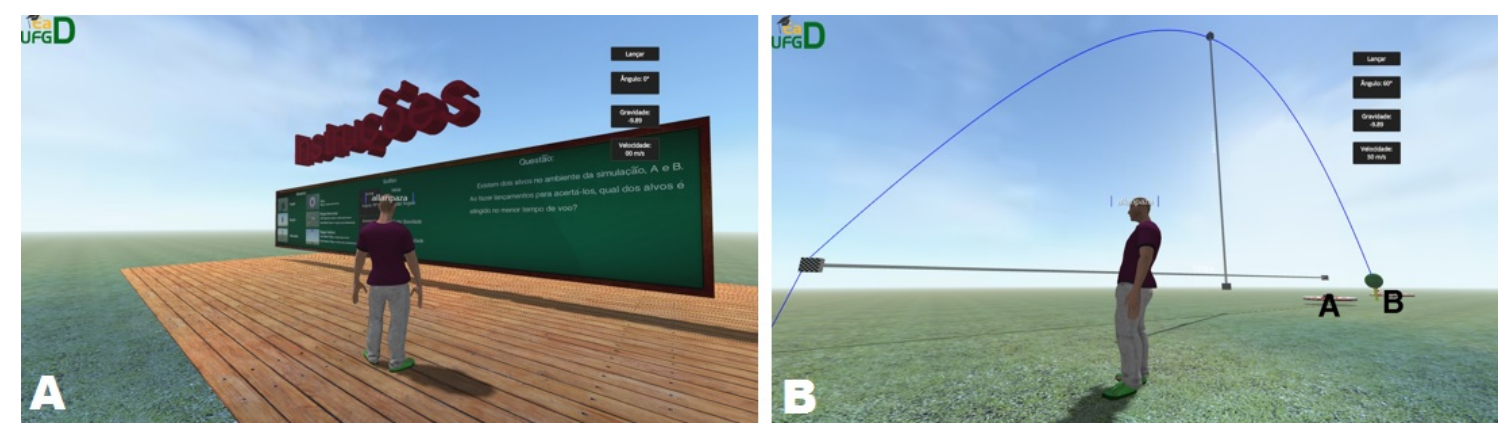

Figura 1. A - Quadro com instruções e a questão de física a ser trabalhada no experimento e B - Visualização da trajetória do objeto durante o lançamento oblíquo.

Para a utilização do simulador os alunos foram organizados em duplas, e distribuídos nos computadores disponíveis, e orientados a buscarem uma resposta para a questão de pesquisa. Foram informados que a interação somente poderia ocorrer com o companheiro(a) de dupla e através da ferramenta chat do Sandbox. Foram formadas 7 duplas, sendo que cada aluno ficou em um computador e sentou em determinada distância do seu companheiro de dupla. Desta maneira, toda a comunicação feita pelos membros da dupla foi realizada pela ferramenta chat do Sandbox. Após ouvirem as explicações gerais da ação e sobre o funcionamento da simulação os alunos iniciaram a atividade na busca de encontrarem respostas a seguinte questão "Existem dois objetos no ambiente da simulação, A e B. Ao fazer lançamentos para acertá-los, qual dos alvos é atingido no menor tempo de voo?". Para resolverem a questão os alunos tiveram 40 minutos. Ao final do experimento os alunos, individualmente, responderam a outro questionário, também online, o qual abordava aspectos sobre a realização do experimento e a retomada da questão apresentada no início da atividade.

Para movimentar o avatar dentro da simulação o aluno usava as teclas direcionais do teclado. Isto permitiu a aproximação do quadro com as orientações. Botões do mouse foram utilizados para ampliar ou diminuir o campo de visão, permitindo observar detalhes da simulação como, por exemplo, o ponto de lançamento ou de impacto do objeto, bem como localizar outros avatares. A modificação dos parâmetros como velocidade inicial, ângulo de lançamento e aceleração da gravidade é feita diretamente nos locais indicados na tela.

Os alunos apontaram facilidades e dificuldades em utilizarem o simulador. Quanto 
as facilidades destacaram que o simulador é interativo e de fácil manuseio, possibilita manusear o projétil e controlar as variáveis envolvidas no experimento. Além disso, os alunos apontaram que a ferramenta de chat possibilitou uma maior interação com o colega colaborando no processo de aprendizagem. Ao todo $79 \%$ dos alunos consideraram que o experimento contribuiu para entender o conceito de lançamento de projétil. A maioria dos alunos apresentou que não teve dificuldade na realização do experimento. Alguns destacaram que a dificuldade estava relacionada à sua falta de prática em ambiente virtual, o que de início dificultou a realização do experimento. Dificuldades isoladas foram identificadas, sendo: "Manusear as réguas para medir as distâncias e altura, pois o computador fica travando", e "Como dificuldade só fui encontrar o botão de lançar no último lançamento, pois, não havia reparado nele, acredito que se os quadros fossem de cores diferentes fosse mais fácil de identificá-los".

\section{Conclusões}

Consideramos que o experimento se mostrou adequado em ser utilizado no ensino do conceito de lançamento de projétil, e também teve uma boa aceitação pelos alunos. No momento em que este artigo foi escrito, a simulação não contava com efeitos da resistência do ar ou ventos laterais na modificação da trajetória. Isto, no entanto, mais do que uma limitação representa uma das vantagens de usar uma simulação na medida em que as variáveis que não estão presentes podem ser motivo de debate colocado pelo professor. De qualquer forma, mesmo em seu estágio atual de desenvolvimento, o Sandbox permite a construção de sofisticadas simulações de fenômenos físicos. Estudos estão sendo realizados para investigar aspectos da aprendizagem colaborativa no desenvolver do simulador de lançamento oblíquo dentro do Sandbox.

\section{Referências}

Arruda, S. M. and Laburú, C. E. (1998). Considerações sobre a função do experimento no ensino de ciências. In NARDI, R., editor, Questões atuais no ensino de ciências. Educação para a ciência., pages 53-60. São Paulo: Escrituras Editora.

Fiolhais, C. and Trindade, J. (2003). Física no computador: o computador como uma ferramenta no ensino e na aprendizagem das ciências físicas. In Revista Brasileira de Ensino de Física, volume 25, n. 3, pages 259-272.

Fonseca, M. et al. (2013). O laboratório virtual: Uma atividade baseada em experimentos para o ensino de mecânica. In Revista Brasileira de Ensino de Física, volume 35, n. 4, pages $1-10$.

Frustaci, T. B., Dobroff, V. C., and Scalco, R. (2007). O laboratório virtual de física. In International Conference on Engineering and Computer Education.

Hohenfeld, D. P. and Penido, M. C. (2009). Laboratórios convencionais e virtuais no ensino de física. In VII Encontro Nacional de Pesquisadores em Educação em Ciências.

Medeiros, A. and de Medeiros, C. F. (2002). Possibilidades e limitações das simulações computacionais no ensino da física. In Revista Brasileira de Ensino de Física, volume 24, n. 2, pages 77-86.

Yamamoto, I. and Barbeta, V. B. (2001). Simulações de experiências como ferramenta de demonstração virtual em aulas de teoria de física. In Revista Brasileira de Ensino de Física, volume 23, n. 2, page 215. 